\title{
Improved Extraction Method to Evaluate the Degradation of Selected PAHs by Marine Fungi Grown in Fermentative Medium
}

\author{
Michel R. Z. Passarini, * Lara D. Sette and Marili V. N. Rodrigues \\ Centro Pluridisciplinar de Pesquisas Químicas, Biológicas e Agricolas (CPQBA), Universidade \\ Estadual de Campinas, Rua Alexandre Cazellato, 999, Vila Betel, 13140-000 Paulínia-SP, Brazil
}

\begin{abstract}
O estudo propõe um método otimizado para avaliar a degradação de hidrocarbonetos policíclicos aromáticos (HPAs) por fungos filamentosos. A adsorção dos HPAs pelo micélio requer o emprego de uma extração exaustiva, normalmente realizada através da combinação de diferentes técnicas aplicadas, separadamente, ao meio líquido e ao micélio. Este trabalho sugere uma simplificação da etapa de extração, reduzindo o tempo de análise e a manipulação da amostra e garantindo a precisão e a exatidão do método. Os HPAs selecionados, pireno e benzo[a]pireno, foram quantificados por cromatografia gasosa usando detector seletivo de massas operando no modo de monitoramento seletivo de íons. O método foi validado apresentando exatidão no âmbito estudado e utilizado para a avaliação do potencial de degradação de HPAs por treze fungos derivados de ambiente marinho. O estudo selecionou o fungo Aspergillus sclerotiorum CBMAI 849 pela capacidade de degradação de $85 \%$ de pireno e $61 \%$ de benzo[a]pireno após 4 e 8 dias, respectivamente, e o fungo Mucor racemosus CBMAI 847 pela capacidade de degradação de $44 \%$ de benzo[a]pireno após 8 dias.
\end{abstract}

An improved method to evaluate the degradation of polycyclic aromatic hydrocarbons (PAHs) for filamentous fungi is hereby proposed. The PAH adsorption through fungal mycelia implies the use of an exhaustive extraction, which is usually performed through a combination of different techniques applied separately to the liquid medium and to the mycelia. This work proposes a simplified extraction procedure with reduced analysis time and sample manipulation, thereby guaranteeing its precision and accuracy. The selected PAHs, pyrene and benzo[a]pyrene, were quantified by gas chromatography using a mass selective detector operating in single ion monitoring mode. The method was validated presenting accuracy within the scope of this study and it was used for evaluating the potential of PAHs degradation by thirteen fungi derived from marine environment. This study selected the fungus Aspergillus sclerotiorum CBMAI 849 for being able to degrade $85 \%$ of pyrene and $61 \%$ of benzo[a]pyrene after 4 and 8 days, respectively, and the fungus Mucor racemosus CBMAI 847 for being able to degrade $44 \%$ of benzo[a]pyrene after 8 days.

Keywords: biodegradation, GC-MS, pyrene, benzo[a]pyrene, marine-derived fungi

\section{Introduction}

Polycyclic aromatic hydrocarbons (PAHs) are natural or anthropogenic compounds that are considered one of the largest groups of polluting compounds. PAHs can cause damage to the environment and to human health due to the production of genotoxic and carcinogenic derivatives by microorganisms and as a result of biotransformation in humans. ${ }^{1,2}$ PAHs are found in plants, soil, sediments, natural and marine water and in the atmosphere. ${ }^{3}$ Due to their hydrophobic nature, the persistence of PAHs in

\footnotetext{
*e-mail: michelpassarini@yahoo.com.br
}

the environment depends on their physical and chemical characteristics. ${ }^{4}$ PAHs can be degraded by photooxidation, chemical oxidation or bioremediation. Since the 1970s, research on the biological capacity of organisms to degrade PAHs has demonstrated that bacteria, fungi and algae have catabolic abilities that may be used for the soil and water remediation contaminated with PAHs. ${ }^{5}$

As a rule, PAHs are biodegraded with more difficulty as their molecular weight increases because their water solubility is decreased. Unfortunately, this increased hydrophobicity usually correlates with increasing genotoxicity and decreasing biodegradability. ${ }^{6}$ Thus, the potential to detoxify PAHs containing four or more fused 
benzene rings by fungi has been examined. ${ }^{7}$ However, the capacity of marine-derived fungi to degrade pollutants such as PAHs has been poorly investigated. The PAHs selected in the present study were chosen due to their high recalcitrance in the environment and because of their toxicity: pyrene (four benzene rings) and benzo[a]pyrene (five benzene rings, Figure 1) are recalcitrant molecules with a long halflife in the soil of 270 days to 5.2 years and of 269 days to 8.2 years, respectively. ${ }^{5}$ In addition, pyrene and benzo[a] pyrene are classified by the United States Environmental Protection Agency of the (USEPA) as a priority pollutant.
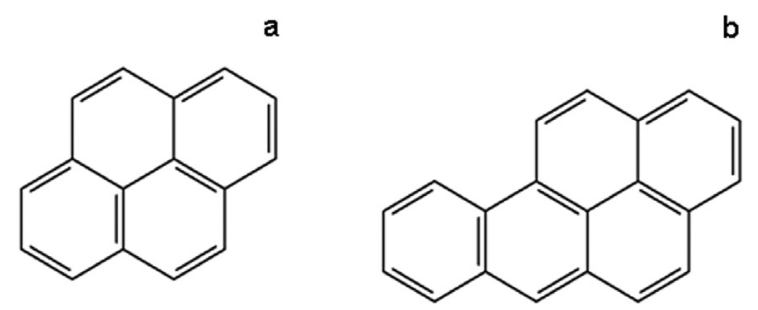

Figure 1. Molecular structure of pyrene (a) and benzo[a]pyrene (b).

The analytical methods commonly used to determine PAHs are high-performance liquid chromatography with a fluorescence or UV detector (HPLC-fluorescence or HPLC-UV) and gas chromatography with mass selective detection (GC-MS). The main advantages of using the GC-MS technique for the quantification of PAHs are its high selectivity when applied in single ion monitoring (SIM) mode and its quantification ability with simultaneous identification of the analyte.

During sample preparation for PAH assays, the extraction and cleaning are considered critical steps because the PAH compounds can be absorbed by fungal mycelia, thus leading to an overestimation of the PAH degradation efficiency. To avoid this problem, the fermentative liquid medium is centrifuged for the analysis of the aqueous phase, and an additional extraction of the obtained residue (mycelium) is carried out. ${ }^{8,9}$ There are different techniques cited in the literature for the extraction PAH samples. ${ }^{6-9}$ The most commonly extraction method is the Soxhlet method, ${ }^{6}$ which has inherent disadvantages such as the large volumes of organic solvents required and the extended duration of extraction ( $c a .16 \mathrm{~h}) .{ }^{8} \mathrm{~A}$ clean-up procedure can then be performed either by solid-phase extraction (SPE) using silica, florisil or alumina ${ }^{10-12}$ or by liquid-liquid extraction. ${ }^{13}$

The main objective of this work was to simplify the sample preparation step to ensure that the decrease of PAH concentrations was not a consequence of the reduction of extraction efficiency resulting from the adsorption of PAH on fungal mycelia. The validated method described here could improve the scientific standards related to evaluating the degradation of PAHs by filamentous fungi; this validated method could also be applied to PAH degradation assays in different environments.

\section{Experimental}

\section{Materials and reagents}

Benzo[a]pyrene (96\%) was purchased from Fluka (Buchs, Switzerland), pyrene (98\%) was purchased from Acros (New Jersey, USA), and dibutyl phthalate (96\%) was purchased from Merck (Darmstadt, Germany) (Figure 1). For sample preparation, the following reagents were used and were of analytical grade: ethyl acetate, Mallinckrodt (Xalostoc, Mexico), dimethyl sulfoxide, Merck (Darmstadt, Germany), anhydrous sodium sulfate, Merck (Darmstadt, Germany); high-purity water produced by Simplicity (Millipore, Bedford, MA, USA) was also used.

The stock solutions of pyrene, benzo[a]pyrene and dibutyl phthalate were used at amounts of $456 \mu \mathrm{g} \mathrm{mL}^{-1}$, $424 \mu \mathrm{g} \mathrm{mL}^{-1}$ and $578 \mu \mathrm{g} \mathrm{mL}^{-1}$, respectively, in ethyl acetate for the chromatographic analyses. The pyrene and benzo[a] pyrene solutions used to prepare the fermentative medium for the degradation experiments were prepared in dimethyl sulphoxide at $2.0 \mathrm{mg} \mathrm{mL}^{-1}$ and $1.0 \mathrm{mg} \mathrm{mL}^{-1}$.

\section{Standard solutions}

Stock solutions of benzo[a]pyrene, pyrene and dibutyl phthalate $\left(400 \mu \mathrm{g} \mathrm{mL}^{-1}\right)$ were prepared by dissolving $10 \mathrm{mg}$ of each reagent in $25 \mathrm{~mL}$ of ethyl acetate; the solutions were kept in brown glass vials at $-18{ }^{\circ} \mathrm{C}$ and remained stable for at least 1 month. Working standard solutions ranged in concentration from 10 to $240 \mu \mathrm{g} \mathrm{mL}^{-1}$ of benzo[a]pyrene

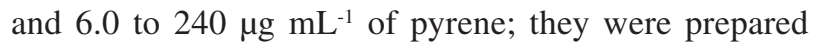
weekly by the dilution of stock solutions in ethyl acetate to obtain the appropriate final concentrations. Dibutyl phthalate was used as an internal standard.

\section{Microorganisms and culture conditions}

In the present study, thirteen filamentous fungi isolated from marine cnidarians were used. They were selected for their ability to decolorize/tolerate the dye Remazol Brilliant Blue R (RBBR) and were taxonomically identified and deposited in the Brazilian Collection of Environmental and Industrial Microorganisms (CBMAI) ${ }^{14}$ (Table 1).

The filamentous fungi were inoculated on Petri dishes with 2\% malt agar (MA2: $20 \mathrm{~g} \mathrm{~L}^{-1}$ and $15 \mathrm{~g} \mathrm{~L}^{-1}$ agar) added $30 \mathrm{~g} \mathrm{~L}^{-1} \mathrm{NaCl}$ and incubated for 7 days at $28^{\circ} \mathrm{C}$. From 
these plates, three fungal culture plugs $(0.5 \mathrm{~cm}$ diameter $)$ from the edge of the colony were transferred to $100 \mathrm{~mL}$ Erlenmyer flasks containing $20 \mathrm{~mL}$ of malt broth $\left(20 \mathrm{~g} \mathrm{~L}^{-1}\right.$ malt extract) added $30 \mathrm{~g} \mathrm{~L}^{-1} \mathrm{NaCl}$; the inoculated cultures were incubated for 7 days at $28{ }^{\circ} \mathrm{C}$. Next, these cultures $(20 \mathrm{~mL}$ ) were used to inoculate $125 \mathrm{~mL}$ Erlenmyer flasks containing $30 \mathrm{~mL}$ of Sabouraud dextrose broth (SDB: $10 \mathrm{~g} \mathrm{~L}^{-1}$ neopeptone; $20 \mathrm{~g} \mathrm{~L}^{-1}$ bacto-dextrose), resulting in a final volume of $50 \mathrm{~mL}$. The flasks were incubated for $48 \mathrm{~h}$ at $28^{\circ} \mathrm{C}$ and were shaken at $150 \mathrm{rpm}$. Then, $2 \mathrm{mg}$ of pyrene and $1 \mathrm{mg}$ of benzo[a]pyrene, diluted separately in $0.5 \mathrm{~mL}$ dimethyl sulphoxide, were added to the Erlenmyer flasks; the resulting cultures were incubated under the same conditions as above for an additional 4-day and 8-day period for pyrene and benzo[a]pyrene, respectively. Control experiments were conducted by incubating pyrene and benzo[a]pyrene in fermentative medium (SDB). The same fermentative medium without the addition of PAHs and without the fungal inoculation was used as a blank..$^{15}$

\section{Sample extraction}

The extraction of PAHs was carried out in fermentative medium $(50 \mathrm{~mL})$ by an Ultra-Turrax system using ethyl acetate as solvent to rupture the fungal cell walls and to remove the adsorbed compounds. For each Erlenmeyer containing the fungus in fermentative medium, $50 \mathrm{~mL}$ of ethyl acetate was added and submitted to cellular disintegration at $14000 \mathrm{rpm}$ for $1 \mathrm{~min}$. The material was then filtered, transferred to a $250 \mathrm{~mL}$ separating funnel and submitted to vigorous shaking for $1 \mathrm{~min}$. The organic phase was filtered by anhydrous sodium sulfate saturated with ethyl acetate directly into a $250 \mathrm{~mL}$ round bottom flask; the aqueous phase was re-extracted with an additional $50 \mathrm{~mL}$ of ethyl acetate. The organic phases were combined and evaporated by vacuum at $40-45^{\circ} \mathrm{C}$ until the volume was reduced to approximately $2 \mathrm{~mL}$. The content of the flask was analytically transferred into a $10 \mathrm{~mL}$ volumetric flask and diluted to the mark with ethyl acetate. An aliquot of $1 \mathrm{~mL}$ of this solution was then diluted in $10 \mathrm{~mL}$ ethyl acetate containing $1 \mathrm{~mL}$ of the internal standard solution before GC-MS analysis.

\section{GC-MS analysis}

GC-MS analysis was carried out on an Agilent 6890N GC (Palo Alto, CA, USA) equipped with an Agilent 7683B autosampler coupled to an Agilent 5975 mass selective detector. Data acquisition and analysis were performed using the standard software supplied by the manufacturer. A fused silica capillary column (HP-5MS, $30 \mathrm{~m} \times 0.25 \mathrm{~mm}$ i.d., $0.25 \mu \mathrm{m}$ film thickness; J\&WScientific, Cologne, Germany) was used for compound separation.

The GC temperature program was as follows: $180^{\circ} \mathrm{C}$, $5^{\circ} \mathrm{C} \mathrm{min}-1$ up to $310^{\circ} \mathrm{C}$, held for $10 \mathrm{~min}$. Temperatures of the injection port and transfer line were set at $290^{\circ} \mathrm{C}$ and $300^{\circ} \mathrm{C}$, respectively. The splitless injection mode was used with the split outlet opened after $3 \mathrm{~min}$, and helium was used as carrier gas at a flow rate of $1.0 \mathrm{~mL} \mathrm{~min}^{-1}$.

Retention times and characteristic mass fragments were recorded, and the chosen diagnostic mass fragments were monitored in the selected ion monitoring mode. The characteristic ions used for quantitation were as follows: benzo[a]pyrene $(\mathrm{m} / \mathrm{z}, 252,126,250)$, pyrene $(\mathrm{m} / \mathrm{z}, 202$, $101,200)$ and dibutyl phthalate $(\mathrm{m} / \mathrm{z}, 149,205,223)$. For quantification, peak area ratios of the analytes to the internal

Table 1. Fungi selected for PAH degradation analysis with collection accession numbers and cnidarians source

\begin{tabular}{lcc}
\hline Marine-derived filamentous fungi & CBMAI accession number & Cnidarians source \\
\hline Mucor racemosus & CBMAI 847 & Mussismilia hispida \\
Aspergillus japonicus & CBMAI 848 & Palythoa variabilis \\
Aspergillus sclerotiorum & CBMAI 849 & Palythoa variabilis \\
Khuskia oryzae & CBMAI 850 & Palythoa variabilis \\
Penicillium sp. & CBMAI 851 & Palythoa variabilis \\
Trichoderma sp. & CBMAI 852 & Palythoa variabilis \\
Penicillium citrinum & CBMAI 853 & Zoanthus solanderi \\
Fusarium oxysporum & CBMAI 854 & Mussismilia hispida \\
Phoma sp. & CBMAI 855 & Mussismilia hispida \\
Paraphaeosphaeria sp. & CBMAI 856 & Palythoa caribaeorum \\
Cladosporium cladosporioides & CBMAI 857 & Palythoa caribaeorum \\
Cladosporium sp. & CBMAI 859 & Palythoa variabilis \\
Eutypella sp. & CBMAI 860 & Palythoa caribaeorum
\end{tabular}

CBMAI = Brazilian Collection of Environmental and Industrial Microorganisms. 


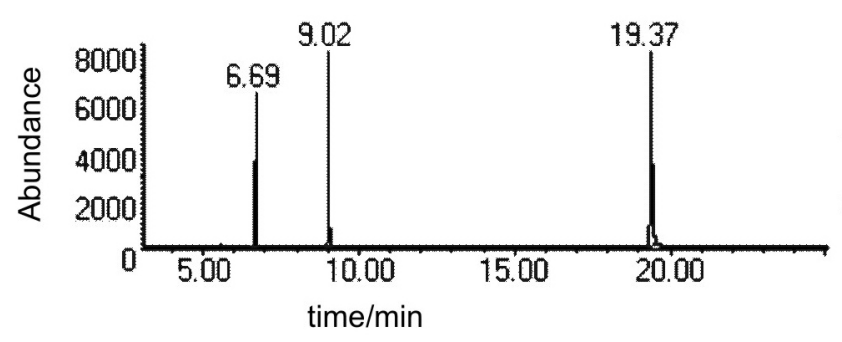

a

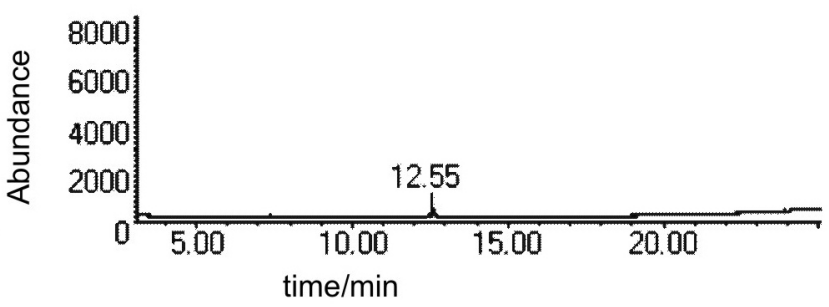

b

Figure 2. Typical chromatograms obtained in SIM mode for: (a) standard solution containing $4.13 \mu \mathrm{g} \mathrm{mL} \mathrm{m}^{-1}$ of dibutyl phthalate $(\mathrm{RT}=6.69 \mathrm{~min}), 4.56 \mu \mathrm{g} \mathrm{mL}{ }^{-1}$ of pyrene (RT = $9.02 \mathrm{~min}$ ), $8.48 \mu \mathrm{g} \mathrm{mL}^{-1}$ of benzo[a]pyrene $(\mathrm{RT}=19.37 \mathrm{~min})$; (b) blank sample.

standard were calculated as a function of the compound concentrations.

\section{Method validation}

In house validation of the method considered the following performance criteria: linearity and linear range, sensitivity, selectivity, precision and accuracy (Tables 2 and 3). The linearity, linear range and sensitivity were established using the analytical curves obtained by the triplicate analysis of pyrene and benzo[a]pyrene at different concentration levels $(0.51 ; 1.28 ; 2.55 ; 6.37 ; 12.8$ and $25.5 \mu \mathrm{g} \mathrm{mL}^{-1}$ and $0.82 ; 2.06 ; 4.11 ; 10.3 ; 21.1$ and $31.6 \mu \mathrm{g} \mathrm{mL}^{-1}$, respectively). The internal standard was dibutyl phthalate at a final concentration of $57 \mu \mathrm{g} \mathrm{mL}^{-1}$.

The precision of the method, expressed as the relative standard deviation of the PAH assay $(n=6)$, was evaluated from the results obtained with the method operating at the same conditions and by using fermentative media containing two concentration levels for pyrene $(0.198$ and $2.05 \mathrm{mg}$ ) and for benzo[a]pyrene $(0.130$ and $1.02 \mathrm{mg})$. The selectivity of the method was evaluated by analyses of the matrix with and without the respective analyte.

\section{Recovery study}

The recovery of the PAHs was determined in fermentative medium containing one of the fungi used in this study. The fermentative medium was spiked (in triplicate) with a benzo[a]pyrene standard solution and a pyrene standard solution, resulting in fortified samples of 7.92, 198, 452, 904 and $1808 \mu \mathrm{g}$ of pyrene and of 13.0, 130, 400,800 and $1200 \mu \mathrm{g}$ of benzo[a]pyrene. The fortification levels represent degradation ranges from 9.6 to $99.6 \%$ for pyrene and 1.64 to $98.9 \%$ for benzo[a]pyrene.

\section{Results and Discussion}

The analytical method used in the present work was successfully applied for evaluating the degradation of selected PAHs by different marine-derived filamentous fungi by GC-MS analysis. This resulted in the selection of two fungal strains (Aspergillus sclerotiorum CBMAI 849 and Mucor racemosus CBMAI 847) capable of degrading up to $85 \%$ of these PAHs.

Figure 2 shows the separation of the analytes (pyrene and benzo[a]pyrene), the internal standard (dibutyl phthalate) and the interference-free chromatogram obtained with the blank sample.

Because PAHs in fermentative medium might undergo adsorption in fungal mycelia, which would lead to overestimated degradation rates, a simplified extraction procedure was proposed. The PAH extraction and cleanup procedures were improved from the method suggested by da Silva et al. ${ }^{15}$ by reducing the amount of solvent used and by promoting the extraction of both the liquid medium and mycelia by using the Ultra-Turrax homogenizer. The Ultra-Turrax system facilitated the analysis because it promoted a higher extracting efficiency through the cellular rupture and intensive shaking. This step solved the problem of PAH adsorption in mycelia and promoted complete PAH extraction.

To minimize the amount of solvent used during extraction, a preliminary test was carried out to establish the number of necessary steps for a satisfactory recovery of the analytes. First, a sample from the fermentative medium (fungus + medium) fortified with $968 \mu \mathrm{g}$ of benzo[a]pyrene and $1208 \mu \mathrm{g}$ of pyrene was used. The Erlenmeyer flasks were maintained for $12 \mathrm{~h}$ in a cooler before being submitted to extraction to promote the adsorption of the analytes in the fungal mycelia. A series of 3 extractions with $50 \mathrm{~mL}$ ethyl acetate was carried out and analyzed by GC-MS. The results obtained by area normalization revealed the efficiency of the first extraction with a recovery of $98 \%$ of the pyrene and $96 \%$ of the benzo[a]pyrene previously added (Figure 3). However, two extractions were established to guarantee an efficiency higher than $99 \%$.

The calibration curve of the individual standards was constructed using seven concentrations $(\mathrm{n}=3)$ by using internal standardization. Good linearity $(r>0.999)$ was 


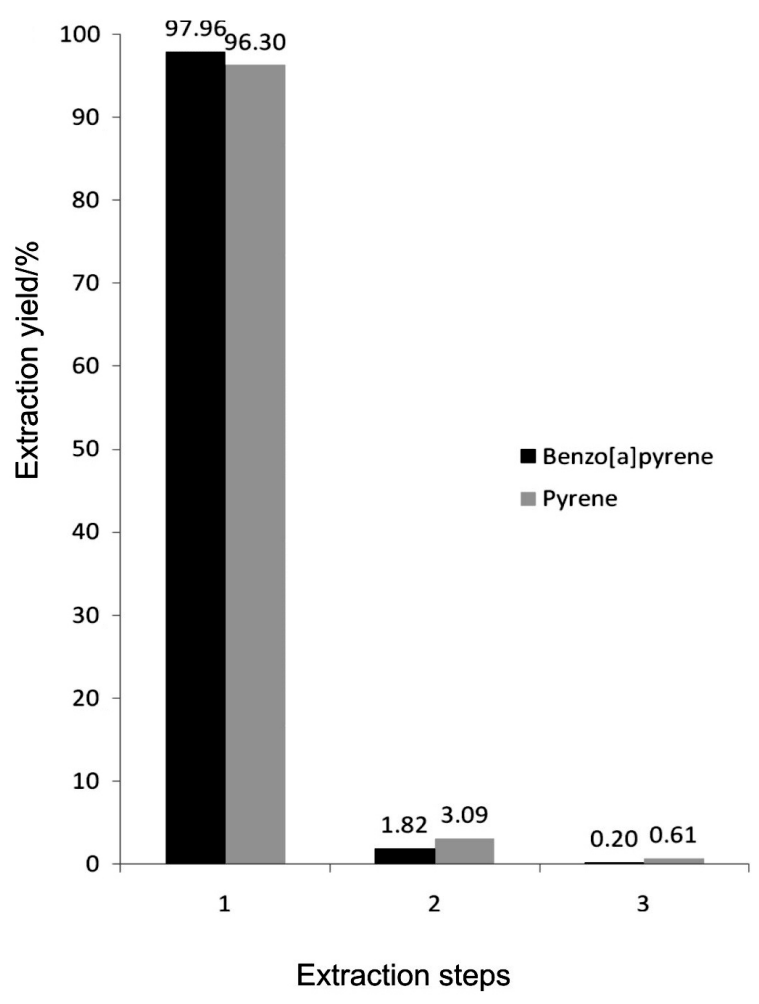

Figure 3. Percentage of PAHs recovered after three extraction procedures. observed in the calibration curves over the concentration ranges investigated.

The repeatability (precision) of the method for pyrene and benzo[a]pyrene was evaluated using the results obtained over one day of operation under the same conditions. Coefficients of variation (CVs) were all less than $10 \%$ for both analytes. Therefore, the GC method is acceptable for evaluating precision.

To evaluate the accuracy of this method, recovery was performed by adding standard solutions at low, medium and high levels to the fermentative medium. The samples $(n=9)$ were then extracted according to the procedure described above and analyzed. The recovery of each component was calculated as the percentage of the net amount of each compound obtained after extraction from that added prior to the extraction. The recovery results are summarized in Table 3. We conclude that the extraction method was efficient enough for the determination of pyrene and benzo[a]pyrene concentrations in fermentative medium.

After the establishment and validation of the analytical method, the thirteen filamentous fungi isolated from marine cnidarians were evaluated with respect to their pyrene and benzo[a]pyrene degradation. These fungi were previously

Table 2. Method validation by GC-MS for pyrene and benzo[a]pyrene quantification

\begin{tabular}{lcc}
\hline Validation parameters & Pyrene & Benzo[a]pyrene \\
\hline Linear range $\left(\mu \mathrm{g} \mathrm{mL}^{-1}\right)$ & $0.5-26$ & $0.8-32$ \\
Sensitivity $\left(\mu \mathrm{g} \mathrm{mL}^{-1}\right)$ & 0.0278 & 0.0095 \\
Coefficient of correlation $(\mathrm{r})$ & 0.9999 & 0.9976 \\
Intercept & -0.0253 & -0.0057 \\
Precision, $\mathrm{n}=6,(\mathrm{CV} \%)$ & 4.96 (fortified with $2.05 \mathrm{mg}$ ) & 5.67 (fortified with $1.02 \mathrm{mg}$ ) \\
& 7.12 (fortified with $0.198 \mathrm{mg}$ ) & 9.08 (fortified with $0.130 \mathrm{mg}$ ) \\
\hline
\end{tabular}

n: number of replicates. CV: coefficient of variation.

Table 3. Recovery test for pyrene and benzo[a]pyrene

\begin{tabular}{|c|c|c|c|c|}
\hline & Amount added $(\mu \mathrm{g})$ & Amount recovered $(\mu \mathrm{g})$ & Recovery $(\%, \mathrm{n}=3)$ & $\mathrm{CV}(\%, \mathrm{n}=3)$ \\
\hline \multirow[t]{5}{*}{ Pyrene } & 7.92 & 7.37 & 93 & 11 \\
\hline & 198 & 164 & 83 & 7.1 \\
\hline & 452 & 402 & 89 & 5.6 \\
\hline & 904 & 759 & 84 & 9.4 \\
\hline & 1808 & 1609 & 89 & 1.3 \\
\hline \multirow[t]{5}{*}{ Benzo[a] pyrene } & 13.0 & 10.8 & 83 & 4.3 \\
\hline & 130 & 112 & 86 & 5.1 \\
\hline & 400 & 368 & 92 & 0.5 \\
\hline & 800 & 784 & 98 & 15 \\
\hline & 1200 & 1080 & 90 & 1.4 \\
\hline
\end{tabular}

$\mathrm{n}$ : number of replicates. CV: coefficient of variation. 


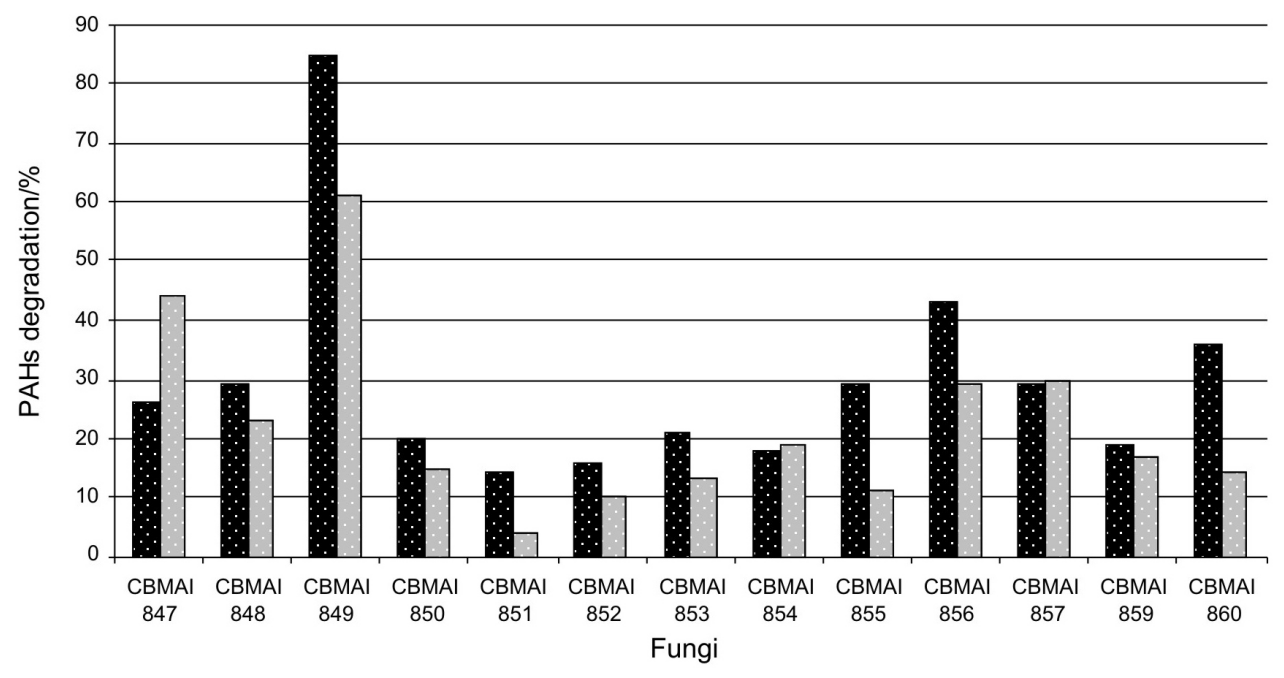

- pyrene degraded (\%) $\square$ benzo[a]pyrene degraded (\%)

Figure 4. Degradation rate (\%) of pyrene and benzo[a]pyrene from thirteen filamentous fungi (see identification in Table 1) isolated from marine cnidarians with the ability to decolorize/tolerate the dye Remazol Brilliant Blue R (RBBR). CBMAI: Brazilian Collection of Environmental and Industrial Microorganisms.

selected according to their ability to decolorize/tolerate the Remazol Brilliant Blue R (RBBR) dye. Because RBBR is a derivative of a PAH compound (anthracene), it was the most suitable for selecting the potential PAH-degrading fungi. ${ }^{15}$ Moreover, a good correlation between RBBR dye decolorization and PAH degradation has been demonstrated. ${ }^{16}$ The results obtained by GC-MS were calculated as a percentage of degradation and are presented in Figure 4 (the recovery results were not used for these calculations).

The marine-derived filamentous fungi presented degradation efficiencies of 14 to $85 \%$ for pyrene and 4 to $61 \%$ for benzo[a]pyrene (Figure 4 ). The ascomycete
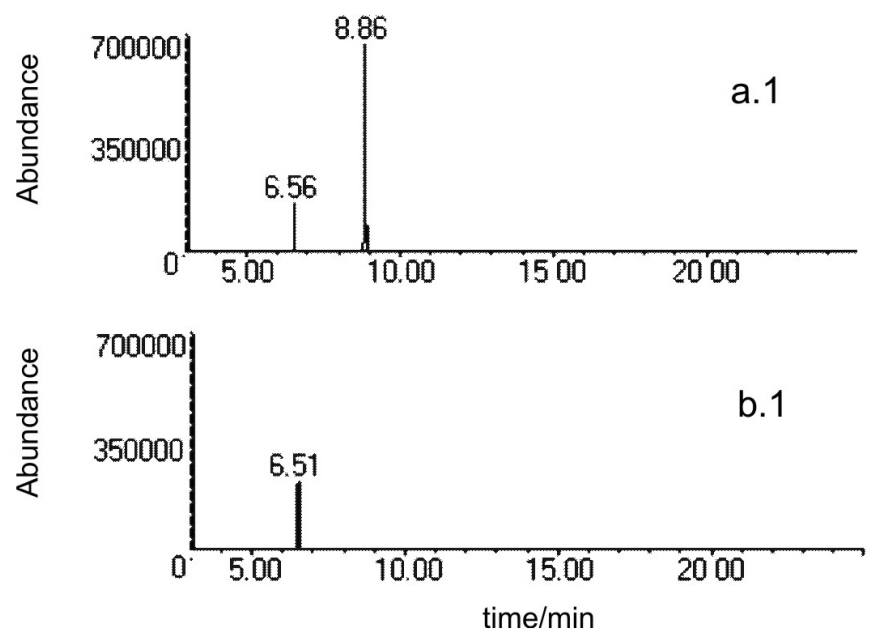

Aspergillus sclerotiorum CBMAI 849 presented the best results of pyrene and benzo[a]pyrene degradation within the scope of this study after 4 and 8 days, respectively. The lower degradation results for benzo[a]pyrene could be explained by its reduced availability for enzymatic attack due to its lower solubility in water. In a previous study reported in the literature, the ascomycete Cyclotirium sp. CBS 109850 was the most efficient fungus in degrading pyrene, with a rate of pyrene transformation of $48.5 \%$ after 4 days. ${ }^{17}$ Cyclotirium sp. CBS 109850 was not able to efficiently degrade benzo[a]pyrene because most of it was absorbed by the fungus $(48 \%) .{ }^{15,17}$ Here, in addition to A. sclerotiorum CBMAI 849, the zygomycete Mucor
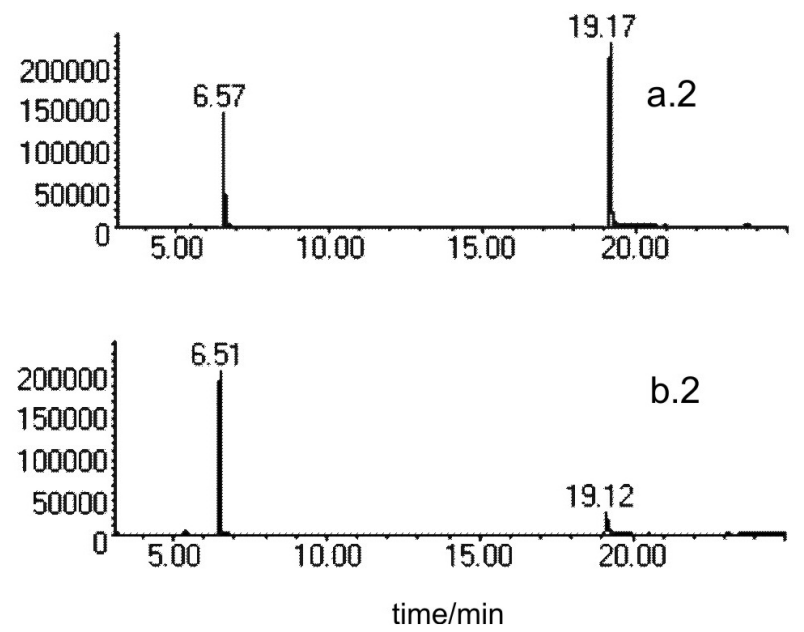

Figure 5. Chromatograms obtained by GC-MS (SIM) of fermentative medium of the fungus Penicillium sp. CBMAI 851 (a) and A. sclerotiorum CBMAI 849 (b) showing the different levels of pyrene and benzo[a]pyrene degradation. (a.1) 14\% of pyrene degradation; (a.2) 4.0\% of benzo[a]pyrene degradation; (b.1) $85 \%$ of pyrene degradation; and (b.2) $61 \%$ of benzo[a]pyrene degradation. IS: internal standard. 
racemosus CBMAI 847 was able to degrade more than $40 \%$ of benzo[a]pyrene after 8 days. The degradation values obtained by the marine-derived fungi were considered satisfactory in comparison with others studies regarding PAH degradation by non-ligninolytic fungi belonging to the ascomycota and zygomycota phyla. ${ }^{18-20}$

In Figure 5, the chromatograms referring to the fermentative media containing the fungi that presented the lowest (Penicillium sp. CBMAI 851) and the highest (Aspergillus sclerotiorum CBMAI 849) results for the degradation of pyrene and benzo[a]pyrene are presented.

\section{Conclusions}

The analytical method, which was optimized and validated in the present study, was selected for the determination of pyrene and benzo[a]pyrene degradation in fermentative medium with a relatively simple and fast method of sample preparation. Method application allowed the selection of filamentous fungi isolated from marine cnidarians as possible degraders of pyrene and benzo[a] pyrene; however, this method could also be applicable for fungi from different environments.

Because the degradation of PAHs containing four or more benzene rings such as pyrene and benzo[a]pyrene has been difficult to achieve, ${ }^{5}$ the fungal isolates $A$. sclerotiorum CBMAI 849 and $M$. racemosus CBMAI 847 could be considered good targets for future studies. These fungal strains not only degrade pyrene and benzo[a]pyrene but would allow the detection and evaluation of the degradative enzymes they produce and the metabolites formed during the PAH degradation process.

\section{Supplementary Information}

Supplementary data are available at http://jbcs.sbq.org.br free of charge, as a PDF files.

\section{Acknowledgments}

The authors thank FAPESP (Fundação de Apoio à Pesquisa do Estado de São Paulo) for financial support.

\section{References}

1. Baborová, P.; Möder, M.; Baldrian, P.; Cajthamlová, K.; Cajthaml, T.; Res. Microbiol. 2006, 157, 248.

2. Netto, A. D. P.; Moreira, J. C.; Dias, A. E. X. O.; Arbilla, G.; Ferreira, L. F. V.; Oliveira, A. S.; Barek, J.; Quim. Nova 2000, 23,765 .

3. Lopes, W. A.; de Andrade, J. B.; Quim. Nova 1996, 19, 497.

4. Planas, C.; Puig, A.; Rivera, J.; Caixach, J.; J. Chromatogr. A 2006, 1113, 220

5. Juhasz, A. L.; Naidu, R.; Int. Biodeterior. Biodegrad. 2000, 45, 57.

6. Gramss, G.; Voiht, K. D.; Kirsche, B.; Biodegradation 1999, 10,51 .

7. Field, J. A.; Jong, E. D.; Costa, G. F.; Bont, J. A. M.; Appl. Environ. Microbiol. 1992, 58, 2219.

8. Rafin, C.; Veignie, E.; Fayeulle, A.; Surpateanu, G.; Bioresour. Technol. 2009, 100, 3157.

9. Anastasi, A.; Coppola, T.; Prigione, V.; Varese, G. C.; J. Hazard. Mater. 2009, 165, 1229.

10. Berg, B. E.; Lund, H. S.; Kringstad, A.; Kvemheim, A. L.; Chemosphere 1999, 38, 587.

11. Belkessam, L.; Lecomte, P.; Milton, V.; Laboudigue, A.; Chemosphere 2005, 58, 321.

12. Zang, S.; Lian, B.; J. Hazard. Mater. 2009, 166, 33.

13. Liu, X.; Bi, X.; Mai, B.; Sheg, G.; Fu, J.; Talanta 2005, 66, 487.

14. Da Silva, M.; Passarini, M. R. Z.; Bonugli, R. C.; Sette, L. D.; Environ. Technol. 2008, 29, 1331.

15. da Silva, M.; Espósito, E.; Moody, J. D.; Canhos, V. P.; Cerniglia, C. E.; Chemosphere 2004, 57, 943.

16. Chroma, L.; Mackova, M.; Kucerova, P.; in der Wiesche, C.; Macek, T.; Acta Biotechnol. 2002, 22, 35.

17. da Silva, M.; Cerniglia, E. E.; Pothuluri, J. V.; Canhos, V. P.; Esposito, E.; World J. Microbiol. Biotechnol. 2003, 19, 399.

18. Potin, O.; Rafin, C.; Veignie, E.; Int. Biodeter. Biodegrad. 2004, $54,45$.

19. Potin, O.; Veignie, E.; Rafin, C.; Microbiol. Ecol. 2004, 51, 71.

20. Ravelet, C.; Krivobok, S.; Sage, L.; Steiman, R.; Chemosphere 2004, 40, 557.

Submitted: February 23, 2010

Published online: November 16, 2010

FAPESP has sponsored the publication of this article. 


\section{Improved Extraction Method to Evaluate the Degradation of Selected PAHs by Marine Fungi Grown in Fermentative Medium}

\section{Michel R. Z. Passarini, * Lara D. Sette and Marili V. N. Rodrigues}

Centro Pluridisciplinar de Pesquisas Químicas, Biológicas e Agricolas (CPQBA), Universidade

Estadual de Campinas, Rua Alexandre Cazellato, 999, Vila Betel, 13140-000 Paulínia-SP, Brazil

Table S1. Degradation rates of the filamentous fungi

\begin{tabular}{|c|c|c|c|c|c|c|c|c|}
\hline \multirow[t]{2}{*}{ Filamentous fungi } & \multicolumn{2}{|c|}{ GC-MS analysis $\left(\mu \mathrm{g} \mathrm{mL}^{-1}\right)$} & \multicolumn{2}{|c|}{ Detected amount (mg) } & \multicolumn{2}{|c|}{ Consumed amount (mg) } & \multicolumn{2}{|c|}{ Degradation rate $(\%)$} \\
\hline & Py & $\mathrm{BaP}$ & Py & $\mathrm{BaP}$ & Py & $\mathrm{BaP}$ & Py & $\mathrm{BaP}$ \\
\hline M. racemosus & 14.8 & 5.6 & 1.48 & 0.56 & 0.52 & 0.44 & 26 & 44 \\
\hline A. japonicus & 14.2 & 7.7 & 1.42 & 0.77 & 0.58 & 0.23 & 29 & 23 \\
\hline Cladosporium sp. & 16.2 & 8.3 & 1.62 & 0.83 & 0.38 & 0.17 & 19 & 17 \\
\hline A. sclerotiorum & 3.0 & 4.0 & 0.30 & 0.40 & 1.71 & 0.61 & 85 & 61 \\
\hline K. oryzae & 16.0 & 8.5 & 1.60 & 0.85 & 0.40 & 0.15 & 20 & 15 \\
\hline Penicillium sp. & 17.3 & 9.6 & 1.73 & 0.96 & 0.28 & 0.04 & 14 & 4 \\
\hline Trichoderma sp. & 16.8 & 9.0 & 1.68 & 0.90 & 0.32 & 0.10 & 16 & 10 \\
\hline P. citrinum & 15.8 & 8.7 & 1.58 & 0.87 & 0.42 & 0.13 & 21 & 13 \\
\hline F. oxysporum & 16.4 & 8.1 & 1.64 & 0.81 & 0.36 & 0.19 & 18 & 19 \\
\hline Phoma sp. & 14.2 & 8.9 & 1.42 & 0.89 & 0.58 & 0.11 & 29 & 11 \\
\hline Paraphaeosphaeria sp. & 11.4 & 7.1 & 1.14 & 0.71 & 0.86 & 0.29 & 43 & 29 \\
\hline C. cladosporioides & 14.2 & 7.0 & 1.42 & 0.70 & 0.58 & 0.30 & 29 & 30 \\
\hline Eutypella sp. & 12.8 & 8.6 & 1.28 & 0.86 & 0.72 & 0.14 & 36 & 14 \\
\hline
\end{tabular}

(Py: pyrene): $2.01 \mathrm{mg}$ added for fermentation. (Bap: benzo[a]pyrene): $1.01 \mathrm{mg}$ added for fermentation. 